\title{
A Study of Form, Meaning and Fuction of Sikka Proverbs
}

\author{
Maria Kartini \\ \{mariakartini1992@gmailcom\} \\ Universitas Hasanuddin Makassar, Indonesia
}

\begin{abstract}
As the part of Indonesia, Sikkanese (Sikka regency people) use their local language in daily communication aside from Bahasa. It is one of strategies to preserve and inherit the culture. There are some forms language which used by Sikkanese in communication and Proverbs is one them which still exist until today. Unfortunately, nowadays many Sikkanese are not familiar with the meaning of several Proverbs, so it leads to several misunderstanding and misinformation. The aims of this study were: (1) to describe the forms of proverbs used by Sikkanese, (2) to find out the meaning of Sikkanese proverbs, (3) to describe the functions of Sikkanese proverbs. The research method of this study was descriptive qualitative method. The data were obtained by interviewing some informants and then recording the spoken data by using a reliable mp3 sound. The procedures in analyzing the data were: 1) transcribed data from oral text into written text, 2) listed and cross-checked the data collected, 3) analyzed the forms, meanings and function of Sikka proverbs and drew the conclusion. Based on the data analysis, it could be concluded that there were four types of Sikka proverbs such as thimble, aphorism, simile and metaphoric which used in daily communication. Moreover, this study revealed that Sikka proverbs contained several norms, advice, warnings, smooth satires which were used to teach and educate Sikkanese.
\end{abstract}

Keywords - Sikka Proverbs, Form, Meaning, Function

\section{Introduction}

As a social creature, human need to interact to other people around them for several purposes. The most dominant feature in interaction is communication. In this kind of interaction, human need a media which is used to help them to convey the meaning and express their idea or feeling. Due to this, human use language as most effective media for communication. Communication is a social event that requires sending and receiving messages with shared understanding of meaning. There are two parties who take a role in this event; they are sender (speaker) and receiver (listener). In the case of understanding of meaning, most of language practices have investigated about misunderstanding which occurs during communication. Humphreys and Jones [1] stated that misunderstanding happens when a hearer (H) fails to understand correctly the proposition (p) which a speaker (S) expressers in an 
utterance (x). Similar perspective comes from [2] which views that a misunderstanding occurs when an interactant chooses an interpretation for some turn which is complete and coherent from his point of view, but it is not the one intended by the speaker. Regarding to this, it can be concluded that when a misunderstanding occurs, the process of transferring the messages cannot be done well because one of the parties in communication is not able to understand the meaning. Referring to this case, misunderstanding also occurs during communication among Sikkanese (people of Sikka regency).

As a media which is used to communicate, Sikkanese use their local language and national language in daily communication. The use of Sikka language as a local language in this globalization era is viewed as an effort to maintain the oral culture. Several forms of Sikka's oral culture inheritances which still exist until this time like traditional songs, poetries, folk stories, legends, myths, idioms and proverbs. As an oral literature, some proverbs commonly occur in Sikkanese's daily speech. [3] Proverb as sentence of the folk that views in a metaphorical, fixed and memorizable form and which is handed down from generation to generation. Meanwhile [3] views a proverb as a traditional, conversational, didactic genre with general meaning, a potential free conversational turn, preferably with figurative meaning. Shortly it can be concluded that proverb is a figurative sentence and phrases of folk that contains wisdom, truth, moral and tradition which handed down from generation to generation.

The beauty of a proverb is not only seen from its figurative language but also from its explicitness message. The study of literature shows that proverb has important position and function in the texts. [4] Two functions of proverbs namely literary function and practical function. As literary function, proverb is considered as a reminder media to reader of the social norms they embody that is, the proverbs can retain its general significance in spite of its being resituated in some text. While as practical function, proverb has some characteristics which makes them useful for everyday purposes. Several purposes counted as like to share memories,teach and persuade. Since the proverbs is considered having power and local wisdom, "the proverbs are also used for treatment for sociopsychological problems such as substance abuse, psychotherapy, tests of mental status, as a way of teaching children to think more abstractly, as an imaginary mnemonic by the elderly, as a means of assessing workers' attitudes about work and life, and even as tests of a defendant's competency to stand trial'. Beside its numerous functions, the proverbs also have several forms. [4] Who analyzed a sample of the proverbs from the oxford dictionary of English Proverbs has distinguished five forms of figurative proverbs such as synecdoche, metaphoric, metonymic, hyperbolic, and paradoxical. Then, some research which is conducted has revealed that these five forms not only occur in English proverbs, but also can be found in another language.

Despite all the beauty of its figurative language and function, some hearer still fail to understand the message that caused by ambiguity and complexity of language use on the proverbs itself. This condition often leads them into misunderstanding and misinterpretation. Due to this reason, half of Sikkanese are ignoring the existence of proverbs and no longer using proverbs in their speech. By considering this phenomenon, this research is addressed to find out and expose the types, meaning and function of Sikka proverbs which commonly occur in daily speech, so it can minimize common misunderstanding happen during communication among Sikkanese. 


\section{Methods}

This research used descriptive qualitative method which used to investigate phenomenon and describe data. This study focused on interviewing, investigating and analyzing the forms, meaning and functions of Sikka proverbs. There were two types of data gathered namely oral data and written data. To collect the oral data, the researcher interviewed some informants using some structured questions, while to get the written data, the researcher used some relevant literatures such as books, journals and dictionaries to support this research. In analyzing the data, the researcher applied some procedures. First, the transcribed data from oral text into written text, second, listed and cross-checked the data collected. Third, analyzed the forms, meanings and function of Sikka proverbs and drew the conclusion. In this research, only selected proverbs were collected as the data; the proverbs which generally emerge and probably emerge during conversation. The informants who were chosen in the research based on four criteria suggested by Nida (1949:190) as follows; 1) the informants were over 20 years old and mastering their own native language, 2) the informants were able to speak both Indonesia language and Sikka language, 3) the informants must be able to give real information freely to researcher, so they should be the native speakers of Sikkanese, 4) the informants should be in good condition so they could give the credible data which needed by researcher.

\section{Result and Discussion}

The findings are divided into four forms of proverbs. Those are thimble, aphorism, simile and metaphor form.

\subsection{Thimble}

A thimble is usually presented in the form of short sentences in the figurative language which has meaning and function as fending, disproving and satirizing. As commonly proverbs, thimble consists of satires, warns, advises, and so forth. There was a proverb found which can be categorized as a thimble.

Hugu gua uma, henot naha kare tua. Umat naha ihin, ihit naha rua witi.

"Women works in the garden, the man should make palm wine. The garden should give yield and it must be carried by two people".

Tua or tuak is an alcoholic beverage made of palms, yeast, and sugar. Umat naha ihin, ihin naha rua witi means that the garden should give yield, and that yield must be carried by two people. It was found there were two types of occupations described in this proverb: farmer and tuak (alcohol) maker. These kinds of works which used as a comparison in this proverb describe job which originally taken by people in this regency. This proverb has a function as advice which containing the message to the bride and groom in fostering a new household. The message that lies in this proverb is about gender equality between the husband and wife. It is stated that to make a living is not only man's responsibility, but also a woman as the spouse having the same responsibility, so both of them are expected to work hard to fulfill their needs. This proverb can be found in the traditional wedding ceremony in the process of handing over the bride to the groom's family, where the father of the bride gave some advice to the newlywed. 


\subsection{Aphorism}

Aphorism is an original thought, spoken or written in a concise and memorable. Aphorism literally means a distinction. One of the famous examples of an aphorism is "Power tends to corrupt, and absolute power corrupts absolutely" (Lord Acton). There were three proverbs which can be categorized as aphorism.

Lemer watu ita mogat, bawak papan ita mogat

"Burying stone together, floating board together"

The word stone refers to a difficult job while board refers to an easy job. Actually, this proverb expresses about cooperativeness. The social characteristic of Sikkanese that still entwined well and found in modern society was cooperativeness between communities. True, societies now and then face problems that evoke strong tensions between citizens, classes and populations. Hence, this proverb is used to persuade and also to teach people to cooperate to achieve a certain purpose or goal. This is supported by ${ }^{[3]}$ that stated since it has the power and wisdom, so it can be used to facilitate memory, teach and persuade people.

Bo'o meha meang, dola meha blara

"Abusing yourself will disgrace you, and hitting yourself will hurt you".

This is the most well-known proverbs and commonly used proverb among Sikkanese. This proverb wants to describe a brotherhood relationship. The meaning of this proverbs is when someone abuses his brother or sister, at the same time he disgraces himself. Commonly, this proverb delivered by the parents to their children as a lesson to preserve the relationship between one and another. By conveying this proverb, the parents expect that their children could respect one another. Moreover, in the framework in the extended family, Sikkanese have such big respect for family and relatives. So this proverb is also used to encourage Sikkanese to keep close to their family.

Tora meten ita gete, tora paot ita mosan. Not lala ele nora, rabek ele genang.

"We have great expectation, but it could not be realized".

The phrase of tora meten ita gete and tora paot ita mosan have a similar meaning. Both of them can be translated as a great expectation. While the phrases not lala ele nora and rabek ele genang mean an expectation does not meet reality. This proverb describes someone's big regret when something happens beyond his expectation. Hence, there are two particular functions of proverbs in given situations. This proverb takes place as a tool to express the speaker's feeling which refers to disappointment expression if speakers personally experience this feeling. Using this proverb in conversation could help the speaker to convey his meaning indirectly when he could not stating the truth directly to the hearer due to some factors. Meanwhile, it can be used to educate the listener since the speaker does not experience this feeling. By conveying this proverb, the speaker is teaching the listener to be elate facing all things which go differently with his or her expectations.

\subsection{Simile}

Simile is a rhetorical figure expressing comparison or likeness that directly compares two objects using some connective words such as like, as, so, that, and so forth. The connective word used in Sikkanese language is ganu. Ganu means like. In this research, the researcher found that there were five types of simile.

Ganu mu'u dukak anin titir go ke'o

"Like the ripe banana that would shake if only blown up by wind"

In this proverb, the ripe banana refers to a son or a daughter. This proverb is used by parents to illustrating their children's behavior. The specific behavior describing in this proverb is 
laziness. Sikkanese use an expression of ' shake if only blown up by the wind' to describe children's behavior who are willing to work if only asked to work. As a common proverb, in this proverb, the parents deliberately to not directly say that their children are lazy, but they use a modality to describe the nature of the child. When the speakers (the parents) express this proverb, this proverb has a function as a smooth satire for the listener (children). This satire is expected to make the children aware so that they can work without waiting for their parent's orders.

Ganu oti man krageng

"Like lizard which has forked tongue"

In this proverb, a person who always says something contradictive is symbolized by lizards. This is embellished with the phrase of fork tongue that describes someone who could not be trusted. Apart from using the proverbs as advice, this proverb used as an allusion for a dishonest person. In the other context, the function might change as a warning. This proverb wants to warn us not to be credulous to these people because sometimes they can take advantage of us.

Ganu ahu nobe nuhun

"Like a dog wears a mortar"

Mortar is a rice pestle made of wood. Commonly, when Sikkanese are pounding rice, there are many pets (in this case a dog) that roam around the place. The dogs love to put their heads into the mortar for searching food inside the appliance. However, because of the narrow mouth mortar sometimes the dogs cannot pull out their heads of the mortar. This illustration associated with someone does something that ultimately harms himself. The function of this proverb is to advise us to always be careful in doing something. Before doing something we have to think twice about the possible risks that could endanger ourselves.

Gu'a ganu ata maha, goa ganu ata ratu.

"Working like mercenaries (slave) will eat like a nobleman"

In ancient times, Sikka regency was known as a village that had a system of nobility. The nobles generally have slaves (indigenous people) to do various kinds of work for them. This proverb wants to convey a message of hard-working to get success and a bright future. The function of this proverb is as an encouragement to people especially young people to work hard to be successful in life.

Tutur doi-doi ganu hepun papan men. Harang set ganu hewon,ganu hewon tua wutun.

Speaking quietly like mosquitos in the board. Mumbling softly like beetle, like beetle up of palm tree.

Unlike the previous proverbs,Sikkanese prefer to use these insects in this proverb rather than other animals. The key message on this proverb lies in descriptions of the sounds produced by both insects. As we know, these insects are able to produce lower frequency vocalization than smaller animals that sounds like buzzing or whining sounds. These sounds are a representation of a family's situation when going through the a hard time. This proverb wants to convey the Sikkanense to keep their personal or family matter away from those who have no business dealing with the problem. Moreover, there is a rule contains in this proverb that does not let anyone who living outside your house know what is going on inside your house. This proverb has a rule for those who believe in it. In related to a most human characteristic which always exaggerating the issues, it is believed that letting others know the problem will only worsen the situation. 


\subsection{Metaphoric}

Metaphoric is a figure of speech that describes a subject by asserting that it is, on some point of comparison, the some as another otherwise unrelated object. This compares two unlike things. Metaphor does not use any connective words such as "like" and "as". In this form of proverb, there was one proverb that can be found.

Ahu plari ele menong nora i'ur.

"A dog runs without looking back his tail"

This is one example of Sikka proverbs taken from general habits that found in daily life and this proverb takes a general habit of a dog. Sometimes, when a dog gets something to eat, it is running away. This proverb refers to someone who forgets his family or friend after attaining glorious success. There is an English proverb that has a similar meaning to this proverb that is leaving after having fun. This proverb has a function as a satire that contains a lesson. The lesson that can be taken from this proverb is being arrogant after having everything is useless because money and wealth are searchable but a happy family and faithful friends are difficult to find.

\section{Conclusion}

Proverbs to be concise having an explicit message, being instructive and influence the addressee have applied for a long time among different generations. This study reveals that there are four forms of Sikka proverbs such as thimble, aphorism, simile and metaphoric which used in daily communication. The most widely used proverb is "bo'o meha meang dola meha blara" that literally means that abusing yourself will disgrace you and hitting yourself will hurt you. Semantically, this proverb describing how to treat relatives and this was used as a lesson. Moreover, this study revealed that Sikka proverbs contained several norms, advice, warnings, smooth satires which were used to teach and educate Sikkanese. Moreover, Sikka proverbs were used to control social behaviors as well as being the tools to strengthen social relationships. By seeing several values and function of the proverbs, it can be drawn that proverbs must be preserved through genenations because the proverbs can control how people behave, think and their beliefs.

\section{References}

[1] M. Sayer, I., "Misunderstanding and Language Comprehension," Journal of Procedia: Social and Behavioral Sciences, vol. 70, pp. 738-748, 2013.

[2] L. Ardissono, G. Boella, and R. Damiano, "A Computational Model of Misunderstandings in Agent Communication," $A I * I A$.

[3] A. Dabaghi, E. Pishbin, and L. Niksanab, "Proverbs from the View Point of Translation.," Journal of Journal of Language Teaching and Research, vol. 1, no. 6, pp. 807-814, 2010.

[4] R. Honeck, A proverb in mind: the cognitive science of proverbial wit and wisdom. USA: Lawrence Erlbaum, 1997. 